\title{
Teoría arqueológica y crisis social
}

\author{
Archaeological theory and social crisis
}

\author{
Almudena Hernando \\ Departamento de Prehistoria \\ Universidad Complutense de Madrid \\ 28040- Madrid. \\ hernando@ghis.ucm.es
}

Recibido: 04-09-2012

Aceptado: 24-10-2012

\section{RESUMEN}

En este texto se defenderá que la crisis por la que atraviesa la sociedad occidental y la crisis epistemológica en la que se halla sumida la arqueología están íntimamente conectadas. Ambas son expresión de un mismo orden de saber-poder (en términos de Foucault) que se rige por la disociación razón-emoción, por la idealización de la razón y por la negación de la importancia de la emoción. Este orden lógico, que fue elevado al lugar de la verdad por la Ilustración, es el orden patriarcal. En el texto se intenta demostrar la vinculación y mutua determinación entre el discurso que hacemos sobre el pasado y el orden socio-económico que rige el presente, y se defiende que, en consecuencia, los arqueólogos tenemos una responsabilidad en la construcción de nuestro futuro que no deberíamos eludir.

Palabras Clave: Crisis modernidad. Orden patriarcal. Razón-emoción. Identidad. Individualidad. Identidad relacional.

\begin{abstract}
The aim of this text is to demonstrate that the current socio-economic crisis of the Western World and the epistemological crisis of archaeology are deeply connected. Both are expression of a same order of knowledge-power (in Foucault terms), characterized by a dissociation between reason and emotion, by an idealization of reason and by a concealment of the importance of emotion. This logical order, raised to the place of the truth by the Enlighment, is the patriarchal order. This text will be focused on the link between the discourse we construct about the past and the socio-economic order of the present. It defends that the archaeologist have a responsibility in the construction of our future which should not be eluded by them.
\end{abstract}

KEY wORDs: Crisis of modernity. Patriarchal order. Reason-emotion. Identity. Individuality. Relational identity.

Sumario: 1. Introducción. 2. La Arqueología y el inconsciente de la cultura (lo "sabido no pensado"). 3. Razón y emoción en nuestra trayectoria histórica. 4. Poder y discurso explícito ("lo pensado"). 5. La identidad relacional actuada (y no reconocida) por los hombres a lo largo de la historia. 6. Conclusión. 


\section{Introducción}

La Arqueología europea vive un estado de desorientación similar al de la propia sociedad, que atraviesa una crisis sin precedentes en la Modernidad. Miramos perplejos y desconfiados a un futuro cuya trayectoria desconocemos, porque se ha roto la lógica que guiaba hasta ahora nuestro proceso de transformación. Se trata de una crisis estructural, profunda, que afecta al propio andamiaje sobre el que se levantaba hasta ahora nuestro edificio cultural, los valores que nos guiaban, las verdades en las que creíamos. La sociedad se debate, angustiada y sin la protección de los dioses que antes la velaban, entre el intento paria de insistir en unos criterios de relación y actuación regidos por la colaboración, los vínculos emocionales, la igualdad en la toma de decisiones y la solidaridad social por un lado, y el triunfo inapelable de los mercados, de los criterios que imponen la explotación de una mayoría subordinada a manos de una minoría cuyo único objetivo es ampliar y reforzar su poder, privilegio y diferencia respecto a esa masa informe de población de la que se abastecen, por otro.

Aparentemente, la Arqueología no tiene nada que ver con esta situación. De hecho, en general se considera que nuestra disciplina es otra víctima más de los daños colaterales de la crisis: descenso de financiación para proyectos, excavaciones, contratos, obras de restauración, organización de seminarios,... Se observa que, al igual que cualquier otra dinámica social o científica, la Arqueología está resintiéndose económicamente de la situación, sin que se relacione este hecho con la desorientación y pérdida de rumbo epistemológico en las que se encuentra inmersa. La mayoría de los arqueólogos que piensan en este tema (siempre una minoría) establecen la misma relación entre crisis económica y Arqueología que la que suponen entre sociedad y cultura material: las segundas son expresiones pasivas, directas, de lo que ocurre en las primeras. En este texto se sostendrá, sin embargo, un argumento diferente sobre esa relación, que ya ha sido defendido desde posiciones postestructuralistas como la llamada Arqueología Simétrica (Olsen 2010; Webmoor y Witmore 2008; González Ruibal 2007; González Ruibal et al. 2011; González Ruibal este volumen): la Arqueología interacciona de forma tan activa con la dinámica social y cultural como la cultura material con las dinámicas de socialización y reproducción social. Es decir, la retroalimentación entre el discurso que hacemos sobre el pasado y el que hacemos sobre el presente es la misma que la existente entre la materialidad y la subjetividad en la cultura. Cada uno de esos términos forma parte constituyente del otro. No tendríamos la subjetivi- dad que tenemos si no utilizáramos la cultura material que utilizamos, ni tendríamos la cultura material que utilizamos si no tuviéramos la subjetividad que tenemos. Para entender a qué me refiero basta con observar cómo el uso de nuevas tecnologías, de internet o teléfonos móviles está cambiando la subjetividad y las relaciones entre las personas, y cómo, a su vez, este cambio está llevando a producir nueva tecnología y nueva cultura material. Diferentes autores (Latour 1993; Callon 1991; Elías 2001: 70) han insistido ya en este hecho, al igual que Giddens (1995), Bourdieu (2007) o Morin (2005) insistieron en la mutua determinación entre sociedad y persona: las personas tienen distintos modos de entender la vida, las relaciones y a sí mismas dependiendo de la sociedad en la que nacen, porque a través de la educación y la socialización, la sociedad determina el modo de ser persona que caracteriza a sus miembros. Pero a su vez, precisamente por los criterios y valores en los que son educadas, las personas transforman a su propia sociedad en cierta dirección, por lo que puede decirse que la sociedad determina el modo de ser persona tanto como el modo de ser persona determina la forma que irá adoptando su sociedad. Piénsese, por ejemplo, en el caso de Mark Zuckeberg y la invención de Facebook (Mezrich 2010): sólo porque el primero había nacido y se había educado en un determinado contexto cultural de clase media norteamericana, y desarrollaba su adolescencia en un ambiente racionalizador caracterizado por ciertas dinámicas de relación social, como es Harvard, pudo concebir Facebook. Pero a su vez, Facebook está cambiando tanto las relaciones y la subjetividad de las personas que en el futuro éstas tendrán necesidades diferentes, que llevarán a invenciones y tecnologías distintas.

Estamos acostumbrados a concebir la cultura como un conjunto de departamentos estancos (la sociedad, la economía, la psicología individual, la cultura material) susceptibles de ser estudiados de forma aislada. Esto nos permite construir la fantasía de que entendemos y controlamos nuestro objeto de estudio, pero en realidad está falseando la realidad de lo que somos, que es mucho más compleja. La cuestión es que si nos decidiéramos a contemplar toda su complejidad, nuestra seguridad ontológica (basada en la convicción de que controlamos el mundo en medida suficiente) se resquebrajaría, por lo que seguimos operando como si la realidad fuera más simple de lo que es. En esto consiste la ciencia clásica que, desde Descartes, Newton y los mecanicistas del siglo XVIII, ha utilizado el modelo de la maquinaria de un reloj como metáfora del funcionamiento del universo (Midgley 2004: 167). Éste se considera integrado por piezas aisladas que se coordinan y ajustan de acuerdo a un "mecanismo" 
que hay que saber desvelar. Posteriores metáforas basadas en átomos, ordenadores o genes (Ibid.: 169-171) no hacen sino actualizar esta visión simplificada del universo, que no tiene en cuenta el hecho de que la propia interacción entre las piezas transforma las cualidades de cada una de ellas.

Del mismo modo en que se produce la interacción entre materialidad y subjetividad o entre sociedad y persona, se produce la que afecta a los discursos sobre el pasado y sobre el presente de una determinada sociedad (González Ruibal 2008 y este volumen; Gnecco y Moro en este volumen). Hacemos un cierto tipo de discurso sobre el pasado porque estamos inmersos en (y creemos verdaderos) un cierto tipo de valores, ideales o normas en el presente. Y porque crecemos modelados por ellos, damos importancia a ciertos aspectos del pasado y no a otros, por lo que rastreamos determinados aspectos de las sociedades pasadas que seleccionamos (sin saber que lo hacemos) porque son los aspectos a los que damos importancia en el presente. Esto quiere decir que si en el presente damos importancia al cambio, al poder, a la individualidad, a la razón,... buscaremos estos rasgos en las sociedades pasadas, sin preocuparnos por entender si esas sociedades también le daban la misma importancia, lo que pone en riesgo la posibilidad de entender sus dinámicas. De hecho, paradójicamente, suele considerarse que las personas que llaman la atención sobre la necesidad de atender a criterios diferentes de los que rigen la sociedad del presente son las que introducen un sesgo subjetivo en la investigación del pasado, porque suele considerarse de tal modo universal el modo particular que tenemos de percibir y relacionarnos con el mundo en el presente que las demás opciones se consideran faltas de rigor y fundamento científico. De ahí que no sea casual que la crisis en el tipo de valores y verdades que han regido hasta ahora el discurso social imperante en el presente se acompañe de una crisis en el tipo de lógica que debe guiar la investigación del pasado. Si se ponen en cuestión los criterios que rigen la sociedad y el pensamiento del presente, se tienen que poner igualmente los que rigen el estudio del pasado.

Y de ahí también que a los arqueólogos nos quepa una responsabilidad que no deberíamos obviar en la reflexión sobre qué tipo de discurso estamos haciendo y cómo repercute lo que hacemos en el futuro que estamos diseñando. Porque pareciera que una mano negra, llamada mercado financiero está conduciendo por sí sola a nuestra impotente sociedad a un futuro tan amenazador como irremediable, no pudiendo luchar contra ello de otra manera que saliendo a gritar impotentes en protestas callejeras, para que alguien escuche nuestra resistencia ante lo que está ocurriendo. Pero lo que está ocurriendo lo estamos diseñando entre todos, aunque no seamos conscientes de ello. Y, de una forma muy significativa, quienes construimos el discurso que rige a la sociedad, es decir, quienes nos dedicamos a teorizar sobre qué es la sociedad, qué es el ser humano, cuáles son los valores a los que hay que dar importancia, cuáles son los mecanismos que explican el cambio social, cómo fueron nuestros orígenes....

Ciertamente existe una conciencia generalizada sobre la importancia que tiene el pasado para la construcción del futuro, pero esta conciencia suele limitarse a abordar la cuestión desde un planteamiento basado en la razón instrumental, donde la arqueología debe proporcionar herramientas útiles para gestionar los problemas del presente y la amenaza del futuro. Cabe situar en este apartado el énfasis en patrimonio y tecnologías de gestión cultural que actualmente se vive en UE (puede verse, por ejemplo, Dawdy 2009). Sin embargo, es difícil encontrar reflexiones que partan de una crítica radical, en la que se analice la relación entre el pasado que construimos y el presente que estamos sufriendo, entre el desmoronamiento del orden que conocíamos hasta ahora y el tipo de lectura que hacemos del pasado. Por esta razón he decidido dedicar este artículo a esa reflexión. Estamos atravesando una crisis de la que saldrá una sociedad distinta, presumiblemente regida por criterios y valores cada vez menos guiados por la solidaridad, la humanidad y las necesidades emocionales y psíquicas de los seres humanos. Estamos yendo a una sociedad que ofrecerá más recursos tecnológicos y económicos a una parte crecientemente menor de la población mundial, que a su vez será cada vez menos compasiva con quienes no puedan disfrutar de esos mismos recursos. Estamos yendo a una sociedad que, en términos emocionales, se caracterizará de forma progresiva por el sufrimiento. Y creo que puede demostrarse que los arqueólogos tenemos una parte de responsabilidad en esta trayectoria (véase González Ruibal en este volumen). A ello dedicaré las siguientes páginas.

\section{La Arqueología y el inconsciente de la cultura (lo "sabido no pensado")}

La Arqueología historicista no presta atención al significado de la cultura material dentro del conjunto de relaciones de la cultura, por el simple hecho de que no contempla las relaciones de la cultura. La Arqueología procesual, por su parte, considera que todas las relaciones que integran la cultura son analizables en términos de "sistema socio-económico" (Binford 1972; Renfrew 1988) y que este sistema está guiado siempre por la misma lógica que rige 
el presente, que es la lógica economicista que intenta maximizar los resultados de cualquier acción (Fernández Martínez, este volumen). La cultura material no sería sino el resultado pasivo, el efecto, la consecuencia, la manifestación de la aplicación de esa lógica en condiciones distintas, por lo que es interpretada como un indicador del grado de complejidad alcanzado por el sistema, en una suerte de marcador pasivo del mismo (Binford 1965). La Arqueología posprocesual, por su parte, vino a transformar la idea que teníamos de la función de la cultura material dentro de la cultura cuando demostró (Hodder 1982; 1988) la relación interactiva que establece con la propia construcción social, dado el valor de los objetos como "símbolos en acción". Los objetos serían significantes de un significado simbólico a través del cual la cultura expresa mensajes que no son conscientes, ni por tanto, pueden ser expresados de forma discursiva. Como veremos a continuación, aunque coincido con esta interpretación de la cultura material, no lo hago, sin embargo, con otros aspectos de la interpretación posprocesual. Al partir de la prioridad que el pensamiento posmoderno concede al sujeto transcendental, es frecuente que los arqueólogos posprocesuales atribuyan a todas las personas, independientemente del grado de complejidad de su grupo social, la misma capacidad de agencia y por tanto, la misma individualidad que caracteriza a los sujetos de la modernidad (Moore 2000; Knapp y Meskell 1997; Knapp y Van Domelen 2008; Machin 2009). Y es aquí donde reside, en mi opinión, el principal problema de sus interpretaciones del pasado. Sus posiciones son, en principio, anti-positivistas, por lo que consideran que la lógica y los códigos de significado de cada grupo humano son particulares e intransferibles, lo que favorece el relativismo e impide el evolucionismo y el etnocentrismo. Pero al considerar que la individualidad es una forma universal de identidad, están proyectando a todos los grupos humanos el modo de identidad que caracteriza a los hombres de la modernidad, lo que no sólo impide comprender interacciones pasadas basadas en otras lógicas, sino que además, reafirma la lógica cultural que nos ha traído hasta el punto crítico en el que nos encontramos.

En este texto se defenderá que la cultura material no es un resultado intencional, consciente, meramente utilitario, una herramienta de la sociedad que la produce y usa, sino que expresa contenidos culturales que no son conscientes, pero que no obstante operan de manera determinante en la construcción de las dinámicas en que nos insertamos, siguiendo con ello la fundamental aportación de la arqueología posprocesual. Pero se irá más lejos aún, al defender que su interacción en el conjunto de la cultura tiene lugar en un nivel más profundo que el simbólico, pues es uno de los elementos que construyen ontológicamente a la persona, por lo que al estudiarla pueden conocerse aspectos de la persona que van más allá de los que ésa puede reconocer o explicar. Fijémonos en la decoración de nuestras viviendas, en la distribución de los muebles de nuestra habitación, en el orden o desorden de nuestros espacios privados, sus colores y el diseño de sus muebles. Ni nuestra ropa ni nuestros muebles ni los colores que utilizamos son resultados pasivos de nuestra subjetividad, y ni siquiera son expresiones simbólicas de contenidos concretos, sino dimensiones a través de las que la propia subjetividad y el sentido del ser son construidos. A través de todas esas dimensiones nos definimos como personas y expresamos lo que somos, sin que podamos justificar las elecciones de forma racional en muchos casos. El hecho de que no podamos explicar por qué nos gustan ciertos colores o ciertos diseños o un estilo de ropa no implica que no interactúen de forma muy activa con nuestra subjetividad, sino simplemente que pertenecen a la dimensión no pensada, no consciente, de lo que somos. Bollas (2009) llamó "lo sabido no pensado" a esa parte de nuestro comportamiento expresada $a$ través de acciones y objetos, y no de pensamientos, que forma parte de nuestra mente inconsciente desde la infancia. A través de una socialización que no siempre es explícita, sino construida a través de la imitación y reforzada o sancionada por los mayores, los niños y las niñas van adoptando modos distintos de expresión corporal, de modalidades de juego, de inclinaciones a colores, formas o disposición de la cultura material que utilizan. Lo mismo sucede entre clases sociales diferentes, y por supuesto, entre culturas distintas. A través de la acción y el uso de cultura material, se reproduce una cierta manera de ser que no es consciente ni pensada, por lo que no pasa a formar parte de lo que una persona puede expresar de sí misma cuando tiene que definir su propia manera de ser. Lo que podemos expresar para definirnos incluye únicamente aquellos comportamientos, actitudes o rasgos que ponemos en juego de forma consciente, pero lógicamente no pueden incluir a aquellos cuya actuación nosotros mismos desconocemos.

Esta misma dinámica opera al nivel de la cultura, porque como ya señalé en otro lugar (Hernando y González Ruibal 2011), considero que la relación entre la persona y la cultura puede calificarse de fractal, en el sentido de que no es de determinación, sino de escala: la cultura está regida por la misma lógica que rige la subjetividad de las personas que tienen el poder dentro de ella, porque son ellas las que construyen el discurso que la rige. Esto quiere decir que el relato de la historia está integrado sólo 
por los hechos y acciones que son conscientes y que son reflexionadas por parte de la gente que la protagoniza (que son quienes están en el poder), quedando excluida de ella toda esa otra parte que las propias personas no reconocen ni, por tanto, pueden reflexionar. Sin embargo, la arqueología analiza el comportamiento humano a través de sus acciones y de la cultura material que ésas generaron o generan, de lo que se deduce que es la disciplina idónea para estudiar los comportamientos "sabidos no pensados" de esos mismos protagonistas y esa parte de la identidad humana construida a través de la acción y los objetos, que no pasa por la reflexión consciente.

Puede ser útil recordar aquí el "Proyecto de la basura" de William Rathje, por el que le concedieron el Premio de la Academia de Ciencias de los Estados Unidos. Rathje (1992) demostró que cuando se preguntaba a familias de la clase media norteamericana por sus hábitos de consumo, no siempre reconocían lo que simultáneamente se encontraba en sus cubos de basura, y que esto no lo hacían porque mintieran, sino porque "la gente (...) desconoce (..) el contenido real de sus vidas" (Ruiz 1992)1. Lo que Rathje demostró es que los cubos de basura ofrecían una información fidedigna y más completa que el discurso hablado, porque la cultura material dejaba constancia de comportamientos que no habían sido conscientes, o al menos no eran reconocidos después, tal vez por no estar bien valorados socialmente o incluso por estar proscritos por la norma social. En este sentido, se podría decir que la Arqueología tiene la capacidad de acceder a evidencias sobre dinámicas y realidades sociales que no son recogidas por la Historia, porque ésta (a pesar de poseer también mucha más evidencia de la que incluye en su discurso, como las posiciones feministas han demostrado) sólo incluye los aspectos reconocidos por la sociedad. Sin embargo, no basta con saber esto para poder interpretar esas evidencias. Para hacerlo, hay que entender esa parte del comportamiento que actuamos en el presente y que, sin embargo, como en los cubos de basura de Rathje, no aparece reflejada en el discurso que rige nuestra sociedad, porque no es reconocida conscientemente. Sólo cuando los arqueólogos empecemos a reconocer esta parte de nuestro propio comportamiento, podremos iluminar aspectos del comportamiento pasado que nuestra mirada no estaba entrenada para ver.

Entiendo la dificultad de aceptar el punto de vista que defenderé aquí por parte de quienes no se han planteado antes esta reflexión. Puede parecer absurdo pensar que hay cosas que están delante de nuestros ojos y que, sin embargo no podemos ver porque el orden social en el que nos incluimos no nos ha enseñado a mirar, pero esto es lo que pretendo argumentar en este texto. La cultura material contiene pruebas de ciertos comportamientos que los arqueólogos no ven ni, por tanto, han podido interpretar hasta ahora, porque ellos mismos actúan esos comportamientos de forma inconsciente, sin reconocer que lo hacen. Con esto quiero decir que nuestro orden social nos enseña a no dar importancia, a no reconocer, determinados aspectos de nuestro comportamiento presente, lo que nos lleva a ser incapaces de reconocer esas dimensiones del comportamiento en el pasado. De ahí que no se pueda separar nuestra subjetividad en el presente del discurso que hacemos sobre el pasado.

\section{Razón y emoción en nuestra trayectoria histórica}

Para entender el proceso histórico, debemos volver a los cazadores-recolectores organizados en bandas. $\mathrm{Al}$ hacerlo, me veo obligada a repetir algunas ideas que vengo desarrollando desde hace tiempo (Hernando 1999), pero resulta necesario hacerlo para poder avanzar un paso más en la argumentación.

Entre los cazadores-recolectores, todas las personas tienen la misma posición de poder -aunque tal vez no de prestigio (Ortner 1996; Rogers 1975; Sanday 1981; Hernando et al. 2011)- y de especialización del trabajo, con la única salvedad de las diferentes y complementarias funciones de hombres y mujeres. En estas condiciones, toda la evidencia sobre sociedades actuales demuestra que el grupo constituye la instancia mínima de identidad, el núcleo último a través del cual puede percibirse a sí misma la persona, porque sólo sintiéndose parte de una unidad mayor puede sentir capacidad de hacer frente a las desconocidas y amenazantes condiciones de la existencia. Esta adscripción al grupo se expresa, entre otras cosas, a través de una cultura material común: la tipología de objetos es limitada y característica del propio grupo (tienen una vestimenta y una ornamentación común que les define, todos los cazadores de un mismo grupo cazan con el mismo tipo de arma, fabrican el mismo tipo de recipientes o de viviendas, practican un rito común,...) (González Ruibal et al. 2011).

Todos los estudios sobre el concepto de persona en estas sociedades demuestran que la idea de uno/a mismo/a se construye sólo a través de las relaciones que se sostienen, y que una persona no sabe quién es si se le hace prescindir de esas relaciones: "yo soy el padre de mi hijo, el sobrino de mi tío, el hermano de mi hermana, el marido de mi mujer..." (Leenhardt 1997; Turner 1995; Taylor 1996).

En estos grupos no existe la escritura, recurso que exige la existencia de un grado elevado de complejidad socio-económica. En consecuencia, la 
percepción y representación de la realidad se construye sólo a través de la experiencia personal, lo que carga de emociones la relación con el mundo. Debe tenerse en cuenta, además, que los fenómenos de la naturaleza no pueden explicarse a través de la ciencia, por lo que se les atribuye comportamiento humano, que es el único tipo de dinámica que se conoce (Campbell 1989; Descola 1996; Viveiros de Castro 1996). Esto es el mito. De esta forma, la relación con el mundo se construye a través de la pura vivencia personal. Sólo existe el mundo que uno conoce personalmente: los límites espaciales sólo incluyen el territorio por el que se ha andado, y los temporales abarcan las memorias personales de los miembros del grupo (Thornton 1980; Dietler y Herbich 1993; Bourdieu 1990; Grebe 1987; Leenhardt 1997; Skar 1981). En todas las relaciones que se sostienen con el mundo existe un componente emocional que lleva a la persona a sentirse parte de una red de relaciones y vínculos (con los demás miembros del grupo, con los fenómenos de la naturaleza porque se consideran regidos por dinámicas humanas, con los muertos que quedan en la memoria,...) que profundiza en la idea de que uno/a es siempre parte de una unidad mayor que sí mismo. Y de esta forma, sienten suficiente fuerza y seguridad en su capacidad de supervivencia.

El comportamiento que caracteriza esta forma de identidad nunca es pensado de forma abstracta, no se reflexiona sobre él, no es objeto de pensamiento, por lo que podríamos decir que, en estos grupos, todo el comportamiento es "sabido no pensado". No se reproduce a través de un conocimiento racional y explícito, ni se analiza a través de ciencias sociales o humanas, sino que se reproduce a través de la imitación de la acción y del uso de objetos (González Ruibal et al. 2011). La ontología del ser, la percepción de uno mismo, no se construye a través de la reflexión o el análisis, sino a través de la acción cotidiana y de la fabricación y uso de cultura material que permiten esa acción. Según demuestran los cazadores actuales, la repetición constante de gestos y acciones les genera una cierta percepción de sí mismos, el sentido de saber quiénes son. Ellos son quienes hacen determinado tipo de flecha, o de cerbatana, quienes usan determinados adornos o ropas, quienes matan a determinadas especies, quienes tienen determinado ritual. Ellos son las acciones que emprenden, y es a través de su repetición cómo se reproduce el orden social. De hecho, será a través de emprender acciones diferentes y de utilizar cultura material distinta como comiencen a diferenciarse los primeros jefes y los primeros especialistas, es decir, como se construyan los rasgos de individualización antes de la aparición de la escritura. En las sociedades orales, uno es lo que uno hace, entre otras cosas a través de los objetos que utiliza, por lo que hacer cosas distintas y utilizar objetos diferentes es la clave de construir diferencias interpersonales, es decir, rasgos de individualización. Estudios realizados por Lúria con hombres analfabetos de Siberia concluían que cuando no se conoce la escritura, las personas no pueden concebirse de forma separada a las circunstancias en las que viven, no pueden concebir un "yo" aislado del grupo ni de sus circunstancias (Ong 1996: 59). Un campesino analfabeto de 38 años, al que Lúria pregunta, por ejemplo, "¿Qué clase de persona es usted?; cómo es su carácter; cuáles son sus cualidades y defectos?", responde diciendo que procede de un determinado pueblo, que está casado y tiene tres hijos, que le gustaría tener más tierra... e identifica sus defectos personales con los problemas que ha tenido su cosecha. Esta manera de entenderse a uno mismo a través de las relaciones que se sostienen y a través de las acciones emprendidas es común en todos los relatos de personas pertenecientes a sociedades orales. En ellas no existe conciencia de la mente ni del pensamiento. Olson (1998: 263) afirma que "el concepto de la mente" fue "una invención griega" acontecida entre el poeta oral Homero y los filósofos Sócrates, Platón y Aristóteles. La Iliada expresaría aún una mentalidad oral (Havelock 1996; Olson 1998), que tras ser transmitida por bardos, habría sido fijada por escrito. En ella "no hay evidencias de un estado de mente diferenciada del cuerpo y están ausentes términos como "decidió", "pensó", "creyó", "dudó" o "se equivocó"” (Olson 1998: 265). Por supuesto que sus protagonistas hacen todas esas cosas, pero no las interpretan como resultado de estados mentales, sino como expresiones de acciones corporales, especialmente de oír voces (de dioses, antepasados, etc.) o de hablar con uno mismo: "reflexionar es mantener una conversación dirigida a (...) (los) órganos internos", como el corazón. De ahí que más tarde, la misma raíz comenzara a desdoblarse en dos conceptos separados, ratio (racionalidad) y oratio (habla) (Ibid: 266).

La identidad y la percepción del mundo antes de la aparición de la escritura no se construyen entonces a través del pensamiento abstracto, de la reflexión, sino a través de la acción y del cuerpo. En la oralidad el pensamiento no se somete a reflexión analítica. Lo que se hace se sabe, pero no se "piensa", en el sentido de que no se somete al tipo de reflexión a la que estamos acostumbrados los que nos relacionamos con el mundo a través de la escritura. No existe algo como "el pensamiento" que se pueda aislar y con el que sea posible relacionarse de forma separada (abstracta) a la relación que se establece con la propia realidad experimentada. La vida, simplemente, se actúa. La actitud reflexiva del propio 
pensamiento sobre sí y la construcción de una idea del "yo" asociado a la mente (cogito ergo sum) derivará del uso generalizado de la escritura para entender el mundo (como veremos más abajo, en ausencia de escritura, la individualidad se construye a través de la particularización del cuerpo, no de la mente). La escritura introduce un nivel de relación con el mundo integrado por las representaciones que hacemos de él, lo que nos permite relacionarnos con esa representación (con las clasificaciones, fórmulas, hipótesis o abstracciones en general sobre el mundo) además de con el mundo en sí, como veíamos más arriba (Olson 1998).

En un proyecto etnoarqueológico desarrollado con los cazadores-recolectores Awá, que habitan en el Amazonas brasileño ${ }^{2}$, pudimos comprender claramente la disociación con la que opera la mente moderna cuando nos resultaba imposible, por ejemplo, preguntar por el sentido de ciertas palabras o el modo de construir alguna expresión. Entre los Awá no es posible reflexionar sobre la lógica del lenguaje, porque el lenguaje no existe como tal. No conciben un nivel abstracto, formado por reglas, palabras, morfemas o sufijos sobre el que se pueda pensar. Lo mismo nos sucedía cuando preguntábamos, por puro afán de curiosidad, si al día siguiente saldrían a cazar y obteníamos respuestas excitadas, defensivas, de claro malestar. No tardamos mucho en entender que no podíamos hacer ese tipo de preguntas, porque para ellos (como para toda sociedad oral) el pensamiento está siempre vinculado a la acción concreta. Preguntarles si saldrían a cazar hacía que se sintieran tan presionados como se sentiría un empleado a quien su jefe preguntara: "¿llevará usted mañana el paquete"? o un/a hijo/a al que su madre preguntara: “ite has lavado las manos?”. En la oralidad no existe el pensamiento abstracto, desconectado de la acción, y aunque cuando pueda darse cierta disociación entre razón y emoción en relación a los fenómenos que se controlan (pues si se controlan es porque se ha descifrado en alguna medida su dinámica y por tanto ya no se la considera humana, por ejemplo en el caso de la agricultura), no se pueden concebir aún leyes generales para representar dinámicas que engloben el funcionamiento de fenómenos concretos diferentes, lo que, en cambio, sí permite hacer la escritura. Es decir, en la oralidad no es posible aislar un nivel de representación del mundo separado de los fenómenos concretos que representa.

En nuestra trayectoria histórica, esta situación inicial fue la base de la que arrancó una creciente diferenciación de posiciones sociales y de especialización del trabajo, encarnadas por los hombres según muestra el registro arqueológico. A medida que se controlaban más fenómenos de (lo que noso- tros denominamos) la naturaleza, esos fenómenos dejaban de considerarse regidos por dinámicas humanas, lo que explica que el poder sobre el mundo se asocie al alejamiento emocional de él, es decir, a una creciente individualización personal (Elías 1993). Cuantos más fenómenos se controlan o entienden a través de mecánicas causales, menos fenómenos son interpretados a través de dinámicas humanas, por lo que más se controla el mundo, pero menos relaciones emocionales se sostienen con él. La individualidad fue resultado de todo un proceso histórico, que se iba desarrollando paralelamente al aumento del control tecnológico y la explicación racional del mundo, dada la distancia emocional que la persona pone en juego cuando desarrolla ambos. Y a su vez, el aumento de la tecnología y la especialización del trabajo iban correlacionándose con el de las diferencias personales dentro del grupo (Elías 1990). Esto quiere decir que el proceso de individualización es la contraparte identitaria del proceso de aumento de complejidad socio-económica, se tenga o no escritura. Las evidencias de aparición de los primeros rasgos de individualización son claros en la prehistoria europea a partir de la llamada "Revolución de los Productos Secundarios", momento en que aparecen las primeras artesanías especializadas (de cobre y oro), la evidencia de relaciones comerciales a larga distancia (a través de la presencia de marfil, por ejemplo), y la producción granjera especializada (Sherratt 1981). La individualización, las diferencias en las posiciones de poder y el control tecnológico irán aumentando (con ritmos distintos y no siempre de forma lineal) hasta el final de la prehistoria, pero el grado en que estos rasgos se pueden intensificar tiene un límite, ya que no existe escritura, ni por tanto fórmulas abstractas o científicas que permitan representar las recurrencias y mecánicas del funcionamiento de los fenómenos de la naturaleza. Es decir, no existe la posibilidad de entender mecánicas abstractas que den cuenta de fenómenos distintos, sino que en ausencia de escritura, cada fenómeno se entiende por sí mismo, lo que establece un límite a la capacidad de explicación y control del mundo. Pues bien, podríamos decir que cuando ese límite se alcanzó en cada contexto histórico, cuando se llegó al máximo grado de objetivación, control tecnológico e individualización que es posible alcanzar sin escritura, esos hombres individualizados inventaron una nueva "tecnología intelectual" (Goody 2000; Ong 1996: 84-7) que les permitió dar salida a la tendencia al aumento de individualidad: a través de la escritura (aunque no de forma inmediata) se disparó el control tecnológico, la explicación racional y la individualidad. El ejemplo de Zuckeberg y Facebook que pusimos al comienzo puede ser útil para pensar en la dinámica 
que pudo caracterizar ese paso: porque la sociedad es de cierto modo, las personas van socializándose con unos ciertos rasgos que les llevan a desarrollar cultura material y tecnología que satisface las demandas de la tendencia, y que a su vez transformará la forma en que se socializarán las generaciones futuras. Esas "tecnologías intelectuales" pueden tener trascendentales (y no planificadas) consecuencias a largo plazo, transformando muy profundamente el modo en que la sociedad entiende el mundo y se entiende a sí misma dentro de él, la forma en que construye su identidad. Esto fue lo que pasó con la escritura, cuyo potencial, una vez desarrollado, transformó de tal manera la capacidad de poder sobre el mundo y el grado de individualidad de las personas, que su uso fue severamente limitado a las mujeres hasta llegar a la modernidad.

La aparición de la escritura transforma toda la percepción de uno/a mismo/a y de la realidad, introduciendo una dimensión nueva a través de la cual relacionarse con ella. Pero resulta necesario entender una idea: su uso no sustituye el modo anterior de relación con el mundo, sino que desdobla la posibilidad de relación de quien la utiliza (Hernando 2012): cuando una persona utiliza la escritura para describir y pensar el mundo, pone en juego dos modos de relación simultáneos: por un lado, sigue relacionándose de forma vivencial directa con los fenómenos que conoce personalmente, y por otro puede relacionarse con la representación de esos fenómenos (clasificándolos, analizándolos, descomponiendo sus partes, imaginando fórmulas matemáticas, físicas o químicas para representar sus mecánicas profundas, etc.). Piénsese, por ejemplo, en la carga emocional asociada a los lugares en los que discurrió la infancia, o de los espacios de la vida cotidiana, indisociables de las experiencias personales que hayan ocurrido en ellos, y en la posibilidad simultánea de incluir esos espacios en mapas o planos abstractos y racionales, en donde esos espacios se mezclan con otros que no hemos conocido ni vivido personalmente. La escritura amplía los límites del mundo, pues permite incluir dentro de ellos todos aquellos fenómenos que alguien ha sabido representar con sus signos, y se asocia siempre a la sensación de poder y de control pues desentraña las mecánicas profundas del universo. Pero no por utilizarla se deja de establecer una relación emocional con los fenómenos que se experimentan personalmente.

El mismo desdoblamiento ocurre en términos de la identidad: a medida que los hombres se individualizaban, la percepción de uno mismo como alguien distinto de los demás y con poder se iba superponiendo a la idea previamente existente de uno mismo como parte de un grupo, pero esta construc- ción de la pertenencia al grupo no desaparecía, porque de ella depende la seguridad ontológica de todo ser humano. La cuestión es que mientras no existió escritura, la individualidad se construía a través de acciones, cultura material y apariencia corporal diferenciada del resto del grupo, superponiéndose, sin embargo, a otras acciones, cultura material y apariencia corporal (que más abajo analizaremos) que, a cambio, unificaban entre sí a esos hombres que se iban individualizando. Pero al aparecer la escritura y convertirse la individualidad en un tipo de identidad consciente de sí, reflexiva (Giddens 1987: 33), pensada (y no sólo sabida), el discurso social (que nos enseña quiénes y cómo somos) que se iba construyendo a través de ella comenzó a reconocer exclusivamente los rasgos relacionados con ella misma, con la individualidad, sin que las acciones, cultura material y apariencia corporal que seguían demostrando la existencia de la identidad relacional entrasen a formar parte del discurso. Y así hemos sido socializados a lo largo de la historia, y lo somos en la actualidad. De este discurso somos resultado los arqueólogos, que por tanto no hemos sido enseñados a ver ni a interpretar, ni en el presente ni en el pasado, las abundantes expresiones materiales de esa irrenunciable identidad relacional.

\section{Poder y discurso explícito ("lo pensado")}

Mi argumento es que a medida que aparecían posiciones de poder, la identidad de quienes las encarnaban (los hombres) se iba desdoblando, manteniendo por un lado la identidad relacional (que garantiza los vínculos y la percepción de uno mismo como parte de una unidad mayor a través, entre otros mecanismos, de relaciones desiguales de género y de asociación en grupos de pares, como veremos más abajo), e introduciendo, por otro, rasgos de individualización, en tanta proporción como elevada y diferenciada fuera la posición de poder que se ocupaba. Ahora bien, la primera forma de identidad es inherente a la impotencia esencial de toda persona aislada, y además no se construye a través del pensamiento sino de la acción; es decir, se asocia a la impotencia y no se reflexiona sobre ella, mientras que la segunda (especialmente a partir de la aparición de la escritura) se asocia a la capacidad de agencia y de poder personal y (desde la aparición de la escritura) es reflexiva. De esta manera, cuando comenzó la individualización masculina -por causas que no son del caso aquí (véase Hernando 2012)-, se habría empezado a desarrollar un discurso de legitimación social que sólo tendría en cuenta los mecanismos de la razón y la individualidad, a pesar de que los de la emoción y los vínculos con el grupo habrían 
seguido actuándose simultáneamente. El desdoblamiento se habría acentuado tanto más cuanto más individualizados estuvieran los hombres, lo que explica que a medida que eso sucediera más se necesitase a (y menos se reconociera la importancia de) las mujeres, por un lado, que seguían encarnando la identidad relacional, y más distancia existiera entre el discurso social (que incluye lo "pensado") y el comportamiento vinculado a la identidad relacional (que incluye lo "sabido no pensado") de los hombres con poder, por otro.

La escritura disparará el proceso, dadas las posibilidades de explicación/control del mundo que permite. De hecho, en el siglo XVII la sensación de control y de individualidad eran tan elevadas en los hombres con posiciones especializadas, que Descartes formuló su célebre cogito ergo sum, identificando el pensamiento (reflexivo, consciente de sí) con el ser. No es casualidad que sea en ese mismo siglo XVII cuando, como ya ha quedado señalado, el concepto de individuo se identificó, por primera vez con el de persona (Morris 1987; Elias 1990: 161 ), porque a través del pensamiento racional cada uno de esos hombres que manejaban la escritura y tenían posiciones especializadas, comenzó a pensar que ya no necesitaba al grupo para sentirse seguro, sino que era su propia capacidad racional individual, su comprensión racional de los fenómenos, la que le permitía controlar el mundo. Pero esta percepción de las cosas es, sencillamente, una fantasía (Hernando 2012).

La Ilustración consagró ${ }^{3}$ la idea de que la sociedad del siglo XVIII era más civilizada y superior a las otras del pasado o del presente porque estaba regida por individuos que no se dejaban llevar por emociones en su relación con el mundo, sino por la objetivadora distancia de la razón. Y el siglo XIX avanzó un paso más al transformar definitivamente los discursos de legitimación, y proponer, a través de la arqueología y la historia, que la seguridad de nuestro grupo era resultado del desarrollo de la razón, el cambio, la tecnología y la individualidad. El discurso sólo tenía en cuenta las dinámicas conscientes, reconocidas, explícitas, pensadas, del comportamiento de los hombres con poder, que son quienes hacían el discurso. Y dejaba fuera todo aquello "sabido no pensado" que ellos actuaban pero sobre lo que no reflexionaban, y con ello, la contribución de las mujeres.

Foucault (1992) ya demostró que el poder se sostiene porque la sociedad considera verdaderos los principios en los que se fundamenta, lo que lleva a su vez a alcanzar el poder a quien cree verdaderos esos principios, potenciándose así el régimen de verdad. El régimen de verdad de nuestra sociedad, basado en la creencia de que la razón sustituyó a la emoción, y el individuo a la comunidad, explica que alcancen el poder aquellas personas (hombres generalmente, pero también mujeres) que creen que semejante fantasía es verdad a pesar de que sea otra la evidencia que rige sus propias vidas particulares. Numerosos autores han puesto de manifiesto la imposibilidad de concebir la razón sin la emoción, o al individuo sin la comunidad (Damasio 2009; Morin 2005), y la categoría de mito a la que cabe adscribir una creencia como ésa (Midgley 2004), en la que se basa el pensamiento científico. La ciencia social positivista considera que puede estudiarse al ser humano en función de lógicas racionales abstractas, como si su comportamiento no estuviera sujeto a condicionantes emocionales, ignorando así lo que cada uno de nosotros sabemos por nuestras propias experiencias vitales. De esta forma, podríamos decir que nuestro orden social está regido por una disociación entre el discurso en el que nos socializamos y nuestra experiencia personal. A través de la escolarización y de la socialización se nos transmiten unas verdades sobre nosotros mismos distintas de las que ven nuestros ojos y experimentan nuestras vidas, pero la fuerza del discurso es tal, que aun así, seguimos reproduciéndolas como verdaderas (sobre el discurso como generador de realidad ver Fernández Martínez en este volumen). Cuando se observa la realidad desde fuera de este discurso que disocia la razón de la emoción (que no es otro que el discurso patriarcal), se tiene la sensación de vivir ante una constante representación teatral de la identidad de quienes están en el poder, como si la vida fuera una salida a escena donde se sigue un cierto guión que, entre bastidores y cuando se vuelve a casa, se sabe fantasioso y no ajustado a la vida real. Y sin embargo, las ciencias sociales y el discurso en el que nos socializamos insisten en que la verdad es la que se cuenta en la escena, y no lo que se sabe que ocurre en la vida real, cuando está en su casa, quien protagoniza esas escenas.

Esa disociación entre lo pensado y lo vivido, entre la verdad del discurso y la de la experiencia, fue aumentando a medida que la individualidad de los hombres era mayor, es decir, a medida que aumentaba la complejidad socio-económica del grupo, adquiriendo carta de naturaleza al comenzar la representación abstracta del mundo a través de la escritura. Podría decirse que a medida que se multiplicaban las funciones y se dividía el trabajo, los hombres que ocupaban las posiciones de poder iban teniendo un doble tipo de comportamiento: por un lado, aquel del que eran conscientes (la individuali$d a d$ ), relacionado con la sensación de agencia personal sobre el mundo y canalizado a través de la razón, y por tanto de la reflexión consciente, de la objetivación y del alejamiento emocional de aque- 
llos fenómenos que controlaban; y por otro, aquel que sabían pero sobre el que no pensaban (la identidad relacional), el que afecta a la experiencia, a las necesidades emocionales, a la propia vida, que se mantenía inalterado, integrado por acciones encaminadas a construir vínculos y sentido de pertenencia a un grupo. Como ambos se rigen por criterios contrarios, y tal como señalábamos, el primero se asocia el poder mientras que el segundo lo hace a la impotencia, resulta fácil entender que a medida que el primero se desarrollaba y se daba importancia a los valores que lo regían (el cambio, la razón, la tecnología), los valores del segundo (permanencia, emoción, vínculos) pasaban a ser desvalorizados por el discurso. Sin embargo, no por ello dejaban de ser actuados (a través de las acciones y la cultura material) por quienes construían ese discurso y elevaban al lugar de la verdad la idea de que la individualidad y la razón eran las únicas estrategias a través de las cuales se construía la seguridad del grupo. Dada la identificación que los hombres con poder iban haciendo con los valores relacionados con la individualidad y la razón, era cada vez más difícil que se identificaran con los asociados a la identidad relacional y la emoción, que sin embargo, les seguían siendo imprescindibles. La solución consistió, en mi opinión, en actuar la identidad relacional sin reconocerlo y sin darle valor social, a través de dos estrategias fundamentales: la asociación de esos hombres en grupos de pares, y el establecimiento de relaciones desiguales de género. A partir del momento en que los hombres comenzaron a desarrollar rasgos de individualización, se comenzaron a asociar entre sí en grupos de guerreros, profesionales, deportivos, por un lado; y por otro, impidieron que las mujeres se individualizaran para que al mantener la identidad relacional garantizaran el vínculo de ellos. Y de esta forma, ellas mantuvieron hasta la modernidad la identidad relacional que al comienzo del proceso caracterizaba a todos los miembros del grupo social. A través de la heterosexualidad normativa, los hombres se aseguraban relaciones complementarias con mujeres especializadas en el sostenimiento de los vínculos, las emociones y las permanencias, dando así satisfacción a ambas formas de identidad sin valorar socialmente ni ser conscientes más que de una de ellas, la individualidad. Paradójicamente, sin embargo, cuanto más importancia daban a ésta (es decir, a la razón, el poder o el cambio), más necesitaban establecer relaciones de pares, y asociarse a mujeres que solo se dedicaran a garantizarles a ellos la otra, lo que explica que cuanto más devaluada está en el discurso la emoción y los vínculos, más patriarcal es la sociedad. No dedicaré las siguientes páginas, sin embargo, a analizar esta última estrategia, sino la primera: la necesidad de asociarse a grupos de pares que fue acompañando el proceso de individualización masculina.

\section{La identidad relacional actuada (y no reconocida) por los hombres a lo largo de la historia}

Todo lo señalado puede ayudarnos ahora a completar el argumento que desarrollamos al principio, vinculando la crisis epistemológica que vive la Arqueología con la crisis estructural que está viviendo la sociedad occidental.

La Arqueología constituye el discurso sobre los orígenes que sustituyó al Mito cuando, en el siglo XIX, la sociedad alcanzó el grado de complejidad socio-económica propio de la Revolución Industrial. Cambio, tecnología, razón, agencia personal,... caracterizaban de tal modo la relación consciente con el mundo de aquellos hombres que regían la sociedad, que el discurso que hacían atravesó un punto de inflexión definitivo, y empezaron a surgir discursos que tenían como eje el cambio, la razón, la tecnología o la agencia personal (Darwin en biología, Marx en sociología, Freud en psicología,...), entre los que se contó un nuevo discurso de origen, construido a través de la arqueología. La estabilidad, la recurrencia, la eternidad, las emociones de los mitos, habían dejado paso al cambio y la razón de la ciencia, adquiriendo ésta la misma potencia de verdad que hasta entonces había tenido el mito.

La Arqueología nació y se ha desarrollado siempre como una más de las disciplinas dedicadas a construir un nuevo orden social, regido por la convicción de que los cambios, la tecnología y el poder, encarnados por hombres crecientemente individualizados, constituyen las claves de nuestra superioridad frente a los demás grupos. La Arqueología se ha dedicado a rastrear el origen y desarrollo de esos rasgos, reafirmando el discurso del presente al ignorar en su análisis del pasado todos los rasgos culturales e identitarios vinculados con la identidad relacional, que por otra parte definían tanto más a las sociedades cuanto menos complejidad socioeconómica tuvieran. Es decir, la Arqueología ha sido una disciplina hecha desde el discurso científico del presente moderno y por tanto desde los criterios identitarios que rigen el poder en la modernidad, definidos por la disociación razón-emoción a la que nos referíamos más arriba. Ciertamente, la arqueología posprocesual cuestionó la dicotomía razón-emoción (e.g. Shanks and Tilley 1992), y defendió la necesidad de atender a las emociones (Tarlow 2000; Gosden 2004; Harris \& Sørensen 2010; Kus 2010), y a expresiones culturales diferentes de las construidas a través de la razón (Atalay 2006). 
Sin embargo, como vimos, simultáneamente insistía en la capacidad de agencia personal asociada a la individualidad como un rasgo universal de todos los seres humanos (Hodder 2003; Dobres y Robb 2000; Knapp y Van Dommelen 2008), lo que impedía analizar la verdadera y trascendente dimensión de las emociones y los vínculos en tanto que materia prima de la identidad relacional. De ahí que ni la Arqueología procesual ni la posprocesual hayan podido rastrear en el registro arqueológico evidencias de la actuación de este tipo de identidad, ni que, por tanto, la atención que la última prestó a las emociones (o a las mujeres o a los indígenas, representantes de la identidad relacional) haya podido transformar el modo de entender la identidad de los hombres en la modernidad. Desde hace algunos años, algunas corrientes feministas están intentando no sólo demostrar la importancia y la contribución de las mujeres a la dinámica social, sino también visibilizar la existencia de dinámicas sociales de permanencia, vínculo y cuidado, y no sólo de cambio, tecnología y poder en el registro arqueológico (Colomer et al.1998; González Marcén y Picazo, 2005; Montón-Subías and Sánchez-Romero 2008), pero sus propuestas quedan lejos aún de ser incorporadas al cuerpo central de la teoría y los objetivos de la arqueología (véase Montón-Subías y Lozano en este volumen).

Es a este tipo de dinámicas a las que me quiero referir, pero insistiendo en un punto poco tratado, en tanto que pretendo argumentar que esas dinámicas sociales orientadas al sostenimiento de los vínculos y el sentimiento de pertenencia a un grupo no sólo han sido protagonizadas por las mujeres a lo largo de la historia (que es lo que, en todo caso, se permite reconocer el discurso), sino también por los hombres. El registro arqueológico está lleno de muestras de la actuación por parte de los hombres de esa identidad relacional, pero esta identidad es tan poco consciente y reconocida por el discurso actual que no aprendemos a verla en el presente, ni por tanto, a poder reconocer sus evidencias cuando aparecen en el registro arqueológico.

Resulta llamativo comprobar que cada vez que en el registro arqueológico aparecen evidencias del proceso de diferenciación social, de la aparición de élites o jefes, de síntomas de individualización masculina, simultáneamente se comprueba una uniformización de la apariencia de esos hombres entre sí. Y sin embargo, mientras los arqueólogos que tratan este tema pueden ver el proceso de individualización en marcha, no dan ningún significado a la uniformización entre pares de la que se acompaña. Recuérdese lo sostenido al comienzo de este texto: la subjetividad de las personas se construye tanto a través de la cultura material como la cultura material es construida de una forma $u$ otra dependiendo de la subjetividad de quien la construye. Los cazadores-recolectores no tienen una idea del "yo", de cada uno de ellos como una instancia concebible fuera del grupo, sino que cada uno de ellos existe en tanto es una parte indisociable de un núcleo último, mínimo, irreductible, que es el grupo social al que pertenecen. Esta percepción de su identidad (relacional) se construye, en gran medida, a través de la uniformización de la apariencia: el hecho de parecer iguales (a través de adornos o decoración corporal específicos para cada grupo) es esencial para generar seguridad ontológica: es el grupo, y no cada uno de ellos separadamente, quien se relaciona como una unidad con el universo.

Como sabemos, las primeras manifestaciones de diferenciación social, y por tanto de ciertos rasgos de individualización masculina, aparecen en el registro arqueológico europeo acompañando a la llamada "revolución de los productos secundarios" (Sherrat 1981). Junto a la introducción del caballo, el buey y determinadas innovaciones tecnológicas empezaron a aparecer en algunos contextos europeos vasos de bebida alcohólica, que según Sherratt (1986: 6-7) se asocian al carro por primera vez en la Cultura de Baden, de la zona danubiana, en la primera mitad del III milenio (2700-2400 a.C.), y representan un nuevo estilo de hospitalidad vinculado al aumento de los contactos interregionales entre hombres aún muy dependientes del mundo mítico, pero que ya utilizan las armas como instrumento y signo de poder. Se han definido sus dinámicas como "economías de bienes de prestigio", porque sus dirigentes compartirían conocimiento ritual y esotérico (dada la enorme importancia que tendría del mundo mítico y la instancia sagrada), además de bienes materiales indicadores de su posición privilegiada (Rowlands 1980; Kristiansen 1982; Bradley 1984: 63; Renfrew y Cherry 1984; Ruiz-Gálvez 1992: 226).

Hacia el 2.500 a.C. empiezan a aparecer enterramientos individualizados de estos primeros jefes en toda Europa occidental, asociándose a un ajuar muy estandarizado y de lujo: junto con el cuerpo inhumado, aparecen las primeras puntas de flecha de cobre y los primeros adornos de oro (demostrando su relación con el control de la metalurgia inicial, la diferenciación de riqueza y la aparición de un poder personal representado por las armas), brazales de arquero y botones de un diseño particular (con perforación en "V"), ambos de marfil (lo que demuestra el comercio con zonas lejanas y un tipo de vestimenta estandarizada), y un tipo de cerámica de lujo, la cerámica campaniforme. A la mayor parte de los autores que se han ocupado del "fenómeno campaniforme" les llama poderosamen- 
te la atención la uniformización de la vestimenta y los ajuares con que se entierran estos primeros jefes desde Escocia hasta Sicilia y desde Portugal hasta Moravia (Sherratt 1987: 87; véase también Garrido Pena 2007 para una revisión de estas teorías), pero curiosamente esa uniformización sólo se interpreta en clave individualizadora, sin tener en cuenta otras dimensiones de la evidencia que muestra. Treherne (1995: 107), por ejemplo, interpreta la aparición de estas tumbas individuales con ajuares de lujo como la evidencia material del paso de una ideología "de comunidad" a una centrada en el individuo y la persona (lo que sin duda ocurre), y diversos autores consideran que representa la aparición de ese "ethos masculino" que ensalza al varón guerrero y que se mantendrá ya durante toda la prehistoria y buena parte de la historia (Treherne 1995: 108; Sherratt 1981: 299; Kristiansen 1984; Kristiansen y Larsson 2005). Ciertamente, a medida que empieza a existir diferenciación en las funciones sociales, no sólo aumenta el control tecnológico del grupo, y por tanto, la sensación de poder de quienes tienen ese control, sino también la percepción de la diferencia interpersonal que se empieza a producir. Ya no todos los hombres hacen lo mismo. Algunos hacen cosas diferentes,.. y tienen más poder. Esta diferencia se visibiliza a través de una apariencia particular, de una nueva estética masculina propia del varón guerrero (Treherne 1995: 125). Pero obsérvese lo que sucede en toda Europa: esta nueva estética corporal, que diferencia a los guerreros dentro de sus grupos de origen, los uniformiza sin embargo entre sí. Kristiansen y Larsson (2005: 231) llaman la atención sobre la similitud de apariencia corporal, reflejada en vestimenta y tipos de armas similares, y el uso de los mismos instrumentos para el cuidado del pelo y la barba (navajas de afeitar y pinzas de depilar), en las "aristocracias guerreras" de toda Europa, desde el Egeo a Escandinavia a partir de la Edad del Bronce. Ellos interpretan esto (también Harrison 2004) como la aparición de "la increíble fuerza aculturadora de una nueva institución de aristocracias guerreras" (Ibid.), pero no prestan atención al significado de esa uniformización en términos identitarios.

En efecto, no sólo el conjunto campaniforme se caracteriza por una apariencia similar de sus élites, sino que la uniformización de la apariencia de los hombres con poder y de los guerreros constituye un rasgo común en la sociedad europea desde la Edad del Bronce. En sus tumbas son característicos los llamados artículos de toilette, dedicados al cuidado del pelo, la barba y la decoración corporal. Se trata de un conjunto integrado por peines de bronce, cuerno o hueso, pinzas de depilar, na- vajas de afeitar, espejos y leznas de tatuaje, todo ello en bronce, que aparece aproximadamente a la vez durante el segundo milenio en toda la Europa central, meridional, septentrional y noroccidental, y se extiende al resto de los territorios en el Bronce Final (Treherne 1995: 110). A juicio de Kristiansen (1984; también en Kristiansen y Larsson 2005 y Harrison 2004) crearían identidad social a través de la alteración de la apariencia corporal, definiendo a los jefes guerreros y a sus seguidores. Esta misma importancia de una apariencia determinada de los guerreros se pone en evidencia en las estelas del Bronce Final del Suroeste de la Península Ibérica, en donde toda su panoplia guerrera (lanzas, arcos y flechas, puñales, espadas, cascos, carros), se ve acompañada, en un muy alto porcentaje de casos, por espejos de bronce (Galán 1993; Harrison 2004). La misma evidencia es destacada en la iconografía de los primeros empresarios surgidos en el Mediterráneo central (la actual Italia), que aprovecharon el colapso de los palacios del Mediterráneo oriental para beneficiarse de las rutas comerciales entre esta zona y el centro/norte de Europa a partir del siglo XIII a.C. (Ruiz-Gálvez 1998, 2009; Kristiansen y Larsson 2005). El ajuar que acompaña a estas personas, que se diferenciaban del resto de su grupo social por su mayor riqueza, estaba integrado por vajillas de mesa, equipo de cocina (para la hospitalidad y convivialidad) y elementos como la navaja de afeitar, asociados a códigos estéticos relacionados con el cuidado de la barba (Ruiz-Gálvez 1998: 107).

Como vemos, los primeros casos de la individualización europea se acompañaron de una simultánea uniformización en la apariencia de quienes se iban individualizando, relacionada a partir de cierto momento (no inocentemente) con el cuidado de la barba, atributo exclusivo de los varones adultos. Esto quiere decir que el registro arqueológico nos muestra dos hechos: por un lado, que la individualidad y el poder se asocian desde sus comienzos a los varones adultos, poniendo en evidencia relaciones desiguales de género. Pero por otro, que el proceso de individualización masculina se acompañó siempre de un establecimiento de relaciones inter pares de quienes supuestamente se individualizaban. Todo ello significa que a medida que los hombres se individualizaban y por tanto, creaban una distancia identitaria con el resto de los miembros de su propio grupo, se iban insertando en grupos de pares, es decir, en grupos de hombres con su misma condición, pertenecientes a los grupos vecinos.

Al identificarse los hombres con poder entre sí como pertenecientes al grupo de los poderosos y visualizar esa adscripción a través de su aparien- 
cia, compensaban el déficit de identificación con el grupo de procedencia que es inherente a la individualidad. Sólo podían abandonar la identificación con un grupo a cambio de adscribirse a otro. Las mujeres expresaban la identidad relacional dentro del grupo a través de los trajes regionales (Sørensen 1997; Hernando 2005), mientras que los hombres actuaban esa misma identidad, pero a través de vínculos con hombres de otros grupos, de forma inconsciente y no visible para los miembros del propio, pareciendo así que la sustituían por la individualidad. Cuanto más consciente y visible era su individualidad dentro del propio grupo, más inconsciente y negada era la identidad relacional que actuaban a través de vínculos con otros hombres en su misma situación.

El traje de chaqueta y corbata sería la expresión más reciente de ese mismo mecanismo. Pensemos en los hombres que poseen detentan el máximo poder económico o político en la sociedad occidental: banqueros, financieros, propietarios de multinacionales o primeras figuras políticas... En este momento dirigen el mundo, por lo que la percepción subjetiva que ellos tienen de su propio poder parece cualquier cosa menos una fantasía. Sin embargo, como hemos dicho, son curiosamente el grupo que más unifica su apariencia a través del traje de chaqueta y corbata, lo que indica, por tanto, su necesidad de adscripción a un grupo de pertenencia, el grupo del poder, para sentirse seguros. Entre la prehistoria y la modernidad, todo tipo de identidades adscriptivas inconscientes, no reconocidas, construidas a través de acciones y apariencias semejantes, ha ido permitiendo a los hombres construir su fantasía de creciente individualidad, facilitando que se consideraran (que se pensaran) progresivamente autónomos y sin necesidad del grupo.

La cuestión es que, como estos hombres eran quienes construían el discurso a través del cual nuestro orden social se reproducía y sostenía, sólo podían incluir en él los valores de los que eran conscientes, por lo que todo el grupo nos socializábamos en una manera de mirar al mundo en la que solo era visible una parte de él... aunque la otra parte estuviera también delante de nuestros ojos.

Como digo, ni siquiera esos autores que, a través de magníficos trabajos, llaman la atención sobre la extraordinaria uniformización de la apariencia de los primeros jefes en toda Europa (Treherne 1995; Kristiansen y Larsson 2005; Harrison 2004; Earle 1994) extraen ninguna conclusión en términos identitarios, quedando completamente ajena la idea de que esa uniformización está expresando identidades colectivas (relacionales) de grupos de pares. Harrison (2004: 59) habla, por ejemplo, de "un código estructurado", que define "la imagen el estatus de un guerrero", y Kristiansen y Larsson (2005: 227) consideran "llamativo" (remarkable) el hecho de que la apariencia de los guerreros de la Edad del Bronce "siga pautas similares desde el Mediterráneo hasta Europa occidental y septentrional", pero la identidad grupal que esto implica no se interpreta en términos de identidad relacional.

Aunque estudios sociológicos sobre la modernidad han insistido en la dimensión relacional masculina inherente a su adscripción a equipos deportivos -fútbol en particular (Brown 1989)- o a la uniformización de los ejércitos (Craik 1997), tampoco cuando la mirada se aplica a la modernidad se suele extraer ninguna conclusión estructural, común a todos los fenómenos observados en la misma dirección, de esa observación. Al igual que sucede en la oralidad, donde la explicación de cada fenómeno es independiente de la explicación de los demás, sin que las inexistentes fórmulas químicas o físicas permitan conectar explicaciones de fenómenos distintos, la dimensión relacional de la identidad masculina sólo se observa a través de sus expresiones particulares, sin que el denominador común que subyace a todas ellas alcance a transformar el discurso social sobre el proceso de individualización masculina. La individualidad sigue siendo el único nivel de identidad percibida por quienes, siempre excepcionalmente, se interesan por la transformación de la identidad (puede verse también Thomas 2004, o en términos históricos Morris 1987 o Weintraub 1993) y cuando se observa evidencia que apunta a una uniformización de la apariencia de los hombres individualizados, y por tanto, a la construcción (inconsciente) de identidades relacionales, sólo se explican los casos particulares en términos funcionales, coyunturales, particulares, lo que impide alcanzar el nivel del significado identitario que puede estar poniendo de manifiesto.

Esto se debe a que el discurso en el que nos socializamos no nos permite imaginar siquiera la existencia de ese nivel. Desde la Ilustración nos enseñan que históricamente la razón sustituyó a la emoción y el individuo a la comunidad, y creemos, con la fuerza con la que se cree en los mitos, que esto es verdad, cuando lo que sucedió es que a medida que se desarrollaba la razón (en tanto que distancia emocional en la relación con el mundo), la emoción y la necesidad de los vínculos persistía con la misma intensidad que habían tenido siempre, pero sin ser reconocidas. No es posible la existencia del individuo sin su anclaje en una comunidad de pertenencia, así que a medida que 
salía de la comunidad de origen, se producían adscripciones a nuevas comunidades identitarias. Así ha pasado siempre y así pasa en nuestra propia sociedad, pero este hecho no se reconoce, aunque lo veamos constantemente a nuestro alrededor, aunque todos y cada uno de nosotros experimentemos la necesidad de los vínculos y las emociones en nuestras vidas privadas.

\section{Conclusión}

Nuestra sociedad está regida por un discurso que emana de la forma en que los hombres han construido su individualidad a lo largo de la historia. Esta forma, a la que yo llamo individualidad dependiente (Hernando 2012), no da valor social a las emociones ni a los vínculos humanos (a pesar de necesitarlos de forma imprescindible y por tanto de actuarlos en las vidas personales). De esta forma, el orden social está regido por políticas que no tienen en cuenta las necesidades y los sufrimientos emocionales, las dinámicas basadas en vínculos, la desestructuración y el sinsentido a los que puede conducir la razón cuando se despoja de la capacidad de empatizar emocionalmente con los demás (Morín 2005: 438; González Ruibal 2008). Numerosos autores, procedentes de disciplinas distintas (Torres López 2010; Bauman 2007; Sennett 2009; Bolstanki y Chiapello 2005; Virilio 2005), están insistiendo en la pérdida de orientación vital a la que puede conducir una sociedad que empuja y premia el cambio, la eficacia tecnológica, la desconexión emocional, el control de información, la apariencia de poder,... y desvaloriza proporcionalmente la solidaridad inherente a los vínculos, la estabilidad y falta de cambio, la capacidad de frenar un ritmo vital cada día más acelerado para poder sentir cómo estamos, qué deseamos, adónde vamos. El sistema en el que vivimos no permite parar, lo que dificulta cada vez más el pensamiento crítico. El mundo académico exige producción a un ritmo acelerado, lo que a su vez obliga a pensar con la lógica del discurso de poder, que niega la importancia de los vínculos y la emoción. Por un lado, porque al estar regida la academia por la lógica científica positivista (expresión de la individualidad dependiente), considera que sólo es aceptable, en tanto que objetivo y científico, aquel modo de razonar que descompone el comportamiento humano en dimensiones computables y observables, como el mecanismo de un reloj. Como ya observara Mary Midgley (2004: 206), el mundo académico suele caer en el error de considerar que el hecho de estudiar subjetividades es en sí mismo subjetivo, lo que podría equivaler a pensar que el hecho de estudiar la locura es loco, o de estudiar la maldad, malo. Obviamente, el rechazo de lo subjetivo constituye una estrategia de saber-poder (en términos de Foucault), que no puede contemplar la idea de convertir en objeto de estudio aquella dimensión que la norma social enseña a desvalorizar en la construcción de la identidad personal.

Los arqueólogos participamos del sostenimiento y reproducción de nuestro orden social tanto como cualquier investigador del presente, porque con nuestros estudios contribuimos a legitimar la idea de que la fuerza y la seguridad de nuestro grupo ha dependido del avance de la individualidad, la razón y la tecnología, olvidando que ese avance no habría sido posible si no se hubiera garantizado el sentimiento de pertenecer a un grupo humano y el cálido arropamiento frente al mundo que proporcionan las emociones. Con ello, colaboramos además en el sostenimiento de un orden patriarcal, que no puede reconocer la importancia de la función que han cumplido las mujeres en la historia (Hernando en prensa; Montón-Subías y Lozano en este volumen). Solo cuando la arqueología comience a poder interpretar las evidencias de la identidad relacional de los hombres en términos de las necesidades emocionales y de su necesidad de sentirse vinculados a una comunidad de pertenencia, comenzará a cambiar el discurso de legitimación del presente. Y esto es condición para que pueda cambiar (junto con otras luchas de diversa índole) el propio presente, porque el discurso que hacemos sobre el presente y el que hacemos sobre el pasado no son sino expresiones de una misma forma de entender al ser humano y a sus dinámicas, que de momento, es la que caracteriza a la que ha sido llamada "masculinidad hegemónica" en la Modernidad (Connell y Messerschmidt 2005; Bird 1996).

En este sentido puede explicarse que la crisis social en la que nos encontramos coincida con una crisis epistemológica de las disciplinas que estudian al ser humano, ya que ambas expresan un mismo fenómeno. Nos educamos y socializamos en la verdad de un discurso construido a través de la disociación razón-emoción, individuo-comunidad, que idealiza el primero de los términos de ambos pares y oculta la importancia del segundo. Las políticas que nos rigen están basadas en esa disociación, sea cual sea el sexo de las personas que lleguen a las posiciones más altas (en mi opinión, el orden patriarcal es un orden lógico, basado en la creencia de que esa disociación es verdad, por lo que no debe confundirse el hecho de que haya mujeres ocupando posiciones elevadas de poder con una disolución de ese orden). Pero este orden está llegando a su paroxismo, lo que hace que los miembros de la sociedad moderna occidental nos veamos sometidos a políticas que no tienen en cuenta las necesidades emocionales de 
las personas, o tal vez debería decirse que no tienen en cuenta que deben ser diseñadas para posibilitar la propia vida de las personas -que incluye esas necesidades emocionales. Estamos regidos por personas (hombres casi exclusivamente) que encarnan la lógica financiera de los mercados, es decir, la de la maximización del beneficio, la racionalización extrema y la desconexión emocional total. Esta misma lógica se acompaña, necesariamente, de un aumento de la desigualdad de género, conflicto social y malestar intrapsíquico. De hecho, la prostitución constituye actualmente la tercera fuente de beneficios en el mundo capitalista y globalizado, sólo detrás del negocio de las armas y de las drogas (Cobo 2007: 81). Los movimientos de reacción social están poniendo en juego, de momento, las claves opuestas, es decir, la emoción y la colectividad, pero no parece que se esté pudiendo encontrar un punto de conexión entre ambos niveles operativos.

Y en mitad de esta cuerda cada vez más tensa entre la disociación que caracteriza por un lado a la lógica de verdad, y en consecuencia a las estrategias político-económico-sociales de nuestra sociedad, regidas por el cambio, la razón y la individualidad, y por otro a la experiencia vital de las personas, regida por la necesidad de que algo permanezca, de pertenecer a redes sociales y de tener emociones sanas, se mueve una teoría arqueológica que no sabe a quién apoyar. Porque dependiendo del paradigma que utilicemos, estaremos reafirmando una determinada visión de los valores que son importantes en la sociedad, seamos o no conscientes de ello. Como decíamos, nuestra lectura del pasado ayuda a construir tanto la sociedad del presente como la manera que tenemos de entender el presente determina la lectura que hacemos del pasado. Los positivistas, sean historicistas o procesuales, apoyan y reafirman la visión del mundo de las políticas que idealizan la razón, el cambio y la individualidad, al utilizar estos ejes para construir su visión del pasado. Los hermenéuticos o posprocesuales comenzaron a reivindicar otra visión de lo humano, dando importancia a la subjetividad y la emoción, aunque al asociarlo a la individualidad cayeron en un relativismo y particularismo extremos y entraron en una dinámica explicativa tan poco fundamentada que sería abandonada por parte de ellos mismos más tarde. Tanto desde esta corriente como desde quienes se situa- ban inicialmente en posturas estructuralistas, se está avanzando últimamente en una dirección que escapa de las bipolaridades cartesianas, disolviendo las antítesis sujeto-objeto, razón-emoción, naturaleza-cultura, cuerpo-mente, sociedad-persona, etc. (Criado 2012; Olsen 2010; Webmoor y Witmore 2008; González Ruibal 2007; González Ruibal et al. 2011; Hernando y Gonzalez Ruibal 2011). Se empieza a defender que las dinámicas humanas son más complejas de lo que hasta ahora ha reflejado la arqueología, lo que convierte la disciplina en un ejercicio necesariamente interdisciplinar y demanda tolerancia a la conjetura. De momento, no se ha consolidado aún el paradigma que permita esta "tercera vía" que quiere escapar de las bipolaridades, de las negaciones y de la absurda pretensión de que la sociedad es una cosa distinta de lo que vivimos.

Podríamos decir que el pulso entre los mercados y los indignados definirá el futuro de la arqueología, y que todo indica que ganarán los primeros y que, por tanto, el positivismo procesual se reafirmará como paradigma dominante (Domínguez Rodrigo 2008). Pero también podríamos decir que si los arqueólogos tomaran conciencia de la disociación en la que se funda el discurso histórico y social (véase González Ruibal en este volumen), y del hecho de que ellos mismos reproducen como verdaderos unos principios que no son los que rigen la vida real, comenzarían a hacer un discurso sobre el pasado diferente, que ayudaría al resto de la sociedad a mirar su presente de forma distinta. Si los manuales sobre la prehistoria y la historia contuvieran interpretaciones sobre los aspectos relacionales de las sociedades del pasado, sobre la importancia de los vínculos y de las permanencias, y no sólo sobre el aumento del poder, el cambio o la tecnología, tal vez, entonces, las políticas públicas se sentirían legitimadas para reconocer y legislar de acuerdo a dinámicas y necesidades humanas, tal como les está pidiendo toda la base social. En mi opinión, tomar conciencia de la ocultación de la importancia de la emoción y de los vínculos humanos es una clave fundamental para poder escapar del futuro terrible al que nos dirigimos. Y en tanto que creadores del discurso sobre los orígenes, que es el principal discurso de legitimación de cualquier grupo social, los arqueólogos tenemos una responsabilidad que no deberíamos eludir.

\section{Notas}

1. La cita completa es la siguiente: "No creo", dice Rathje, "que la gente intente ocultar conscientemente cosas; lo que sucede es que desconocen el contenido real de sus vidas. Por ejemplo, sociedades que beben más alcohol o comen más grasas de lo que dicen" (Ruiz 1992). 
2. Proyecto I+D "Etnoarqueología de los Awá-Guajá (Maranhão, Brasil), un grupo de cazadores-recolectores en transición a la agricultura" (HUM2006-06276Hist). Miembros del equipo: Almudena Hernando, Elizabeth Beserra Coelho, Gustavo Politis y Alfredo González Ruibal. Financiado por el Ministerio de Ciencia yTecnología de España.

3. Utilizo este término religioso porque se admite su verdad con la contundencia de una creencia mítica (Midgley 2004 ).

\section{Referencias Bibliográficas}

Atalay, S. (2006): Indigenous archaeology as decolonizing practice. The American Indian Quarterly, 30 (3\&4): 280-310.

Bauman, Z. (2007): Vida de consumo. Fondo de Cultura Económica, Buenos Aires.

Binford, L.R. (1965): Archaeological Systematics and the Study of Culture Process. American Antiquity, 3(2): 203-210.

Binford, L.R.. (1972): Archaeology as Anthropology. An Archaeological Perspective (L.R. Binford, ed.), Seminar Press, Nueva York: 20-32.

BIRD, S.R. (1996): Welcome to the men's club. Homosociality and the Maintenance of Hegemonic Masculinity. Gender and Society, 10(2): 120-32.

Bollas, Сн. (2009)[1989]: La sombra del objeto. Psicoanálisis de lo sabido no pensado. Amorrortu, Buenos Aires.

Bolstanki, L.; Chiapello, É. (2005): The new spirit of capitalism. Verso, Nueva York.

Bourdieu, P. (1990): Time Perspectives of the Kabyle. The Sociology of Time (J.Hassard, ed.), St.Martin's Press, Nueva York: 219-237.

Bourdieu, P. (2007)[1994]: Razones prácticas: sobre la teoría de la acción. Anagrama, Barcelona.

BradLey, R. (1984): The social foundations of Prehistoric Europe. Longman, Londres.

Brown, A. (1989): Fanatics!: Power, Identity, and Fandom in Football. Routledge, Londres.

Callon, M. (1991): Techno-economic Networks and Irreversibility. A Sociology of Monsters. Sociological Review Monograph (J. Law, ed.), Routledge, Londres: 132-164.

Campbell, A.T. (1989), To Square with Genesis. Causal Statements and Shamanic Ideas in Wayapi. University of Iowa Press, Iowa City.

Сово, R. (2007): Multiculturalismo y nuevas formas de violencia patriarcal. Feminismo y multiculturalismo (C.Amorós y L. Posada Kubissa, eds.), Colección Debate, 47, Instituto de la Mujer, Madrid: 71-84.

Colomer, L.; GonzÁlez Marcén, P.; Montón Subías, S. (1998): Maintenance activities, Technological Knowledge and Consumption Patterns: A View of Northeast Iberia (2000-500 Cal BC). Journal of Mediterranean Archaeology, 11 (1): 53-80.

Connell, R.J.; Messerschmidt, J.W. (2005): Hegemonic masculinity: rethinking the concept. Gender \& Society, 19 (6): 829-59.

Craik, J. (1997): The cultural politics of the uniform. Fashion Theory: The Journal of Dress, Body \& Culture, 1 (2): $127-47$.

Criado, F. (2012): Arqueológicas: La razón perdida. La construcción de la inteligencia arqueológica. Bellaterra, Barcelona.

Damasio, A.T. (2009) [1994]: El error de Descartes. La razón, la emoción y el cerebro humano. Crítica, Barcelona.

DAwDy, S.L. (2009): Millennial archaeology. Locating the discipline in the age of insecurity. Archaeological Dialogues, 16 (2): 131-42.

Descola, Ph. (1996): Constructing natures: symbolic ecology and social practice. Nature and Society. Anthropological perspectives (Ph. Descola, G. Pálsson, eds.), Routledge, Londres: 82-102.

Dietler, M.; Herbich, I. (1993): Living of Luo time: reckoning sequence, duration, history and biography in a rural African society. World Archaeology, 25 (2): 248-60.

Dobres, M.A.; RobB, J. (eds.) (2000): Agency in Archaeology. Routledge, Londres. 
Domínguez Rodrigo, M. (2008): Arqueología neo-procesual: ‘Alive and kicking”. Algunas reflexiones desde el Paleolítico. Complutum, 19(1): 195-204.

EARle, T.K. (1994): Positioning exchange in the evolution of human society. Prehistoric exchange systems in North America (T. G. Baugh, J.E. Ericson, eds.), Plenum Press, Nueva York: 419-38.

Elias, N. (1990): La sociedad de los individuos. Península, Barcelona.

Elias, N. (1993): El proceso de la civilización. Investigaciones psicogenéticas y sociogenéticas. Fondo de Cultura Económica, Madrid.

Elias, N. (2001)[1991]: On human beings and their emotions: a process-sociological essay. The body. Social process and cultural theory (M. Featherstone, M. Hepworth, B.S. Turner, eds.), Sage Publications, Londres: 103-125.

Foucault, M. (1992): Microfisica del poder. La Piqueta, Madrid, 3 a edición.

Galán, E. (1993): Estelas, paisaje y territorio en el Bronce Final del Suroeste. Complutum, Extra, nº 3. Madrid.

Garrido-PenA, R. (2007): El fenómeno campaniforme: un siglo de debates sobre un enigma sin resolver. Acercándonos al pasado: Prehistoria en 4 actos (C. Cacho, R. Maicas, M.I. Martínez y J.A. Martos, eds.), Museo Arqueológico Nacional, Ministerio de Cultura, Madrid: 1-16.

Giddens, A. (1987): Modernidad e identidad del yo. El yo y la sociedad en la época contemporánea. Península, Barcelona.

Giddens, A. (1995)[1986]: La constitución de la sociedad: bases para la teoría de la estructuración. Amorrortu, Buenos Aires.

GonzÁlez Marcén, P.; Picazo, M. (2005): Arqueología de la vida cotidiana. Arqueología y género (M. Sánchez Romero, ed.), Universidad de Granada, Granada: 141-158.

GonzÁlez Ruibal, A. (ed.) (2007): Arqueología Simétrica: un giro teórico sin revolución paradigmática. Complutum, 18: 283-319.

GonzÁlez Ruibal, A. (2008): Time to Destroy. An Archaeology of Supermodernity. Current Anthropology, 49 (2): 247-79.

GonzÁlez Ruibal, A. (2010): Contra la Pospolítica. Arqueología de la Guerra Civil Española. Revista Chilena de Antropología, 22 (2 ${ }^{\circ}$ Semestre): 9-32.

GonzÁlez Ruibal, A.; Hernando, A.; Politis; G. (2011): Ontology of the self and material culture: arrow-making among the Awá hunter-gatherers (Brasil). Journal of Anthropological Archaeology, 30: 1-16.

Goody, J. (2000): The Power of the Written Tradition. Smithsonian Institution Press, Washington.

Gosden, C. (2004): Aesthetics, intelligence and emotion. Implications for archaeology. Rethinking materiality: the engagement of mind with the material world (E. Demarrais, C. Gosden, C. Renfrew, eds.), McDonald Institute for Archaeological Research, Cambridge:33-42.

Grebe, M.E. (1987): La concepción del tiempo en la cultura mapuche. Revista Chilena de Antropología, nº 6: 59-74.

Harris, O.; Sørensen, T.F. (2010): Rethinking emotion and material culture. Archaeological Dialogues, 17 (2): 145-63.

Harrison, R.J. (2004): Symbols and Warriors. Images of the European Bronze Age. Western Academic \& Specialist Press, Bristol.

Havelock, E. A. (1996) [1986]: La musa aprende a escribir. Paidós, Barcelona.

Hernando, A. (1999): Percepción de la realidad y Prehistoria. Relación entre construcción de la identidad y la complejidad socio-económica entre los grupos humanos. Trabajos de Prehistoria, 56(2): 19-35.

Hernando, A. (2005): Agricultoras y campesinas en las primeras sociedades productoras. Historia de las Mujeres en España y América Latina (I. Morant, dir.), Vol. I, Cátedra, Madrid: 79-115.

Hernando, A. (2012): La fantasía de la individualidad. Sobre la construcción sociohistórica del sujeto moderno. Katz, Buenos Aires.

Hernando, A. (en prensa): Change, individuality and reason... or how Archaeology has legitimized a patriarchal modernity. Reclaiming Archaeology: Beyond the tropes of modernity (A. González Ruibal, ed.), Routledge, Londres.

Hernando, A. y González Ruibal, A. (2011): Fractalidad, materialidad y cultura. Un estudio etnoarqueológico de los Awá-Guajá (Maranhão, Brasil). Revista Chilena de Antropología, 24: 9-61. 
Hernando, A.; Politis, G.; González Ruibal, A.; Coello, E.B. (2011): Gender, power and mobility among the Awá-Guajá (Maranhão, Brasil). Journal of Anthropological Research, 67(2): 189-211.

Hodder, I. (1982): Symbols in action. Ethnoarchaeological studies of material culture. Cambridge University Press, Cambridge.

Hodder, I. (1988): Interpretación en Arqueología. Corrientes actuales. Crítica, Barcelona.

Hodder, I. (2003): Archaeology beyond Dialogue. The University of Utah Press, Salt Lake City.

KnApP, A.B.; Meskell, L. (1997): Bodies of evidence on prehistoric Cyprus. Cambridge Archaeological Journal, 7:2: $183-204$

Knapp, A.B.; Van Dommelen, P. (2008): Past practices: rethinking individuals and agents in Archaeology. Cambridge Archaeological Jorunal, 18(1): 15-34.

Kristiansen, K. (1982): The formation of tribal systems in Later European Prehistory: Northern Europe 4000-500 B.C. Theory and explanation in Archaeology (C. Renfrew, M.J. Rowlands, B. A. Seagraves, eds.). Cambridge University Press, Cambridge: 241-280.

Kristiansen, K. (1984): Ideology and material culture: and archaeological perspective. Marxist Perspectives in Archaeology (M. Spriggs, ed.), Cambridge University Press, Cambridge: 72-100.

Kristiansen, K.; Larsson, T.B. (2005): The Rise of Bronze Age Society. Travels, Transmissions and Transformations. Cambridge University Press, Cambridge.

Kus, S. (2010). The matter with emotions. Archaeological Dialogues, 17 (2): 167-72.

Latour, B. (1993): Nunca hemos sido modernos. Ensayo de antropología simétrica. Debate, Madrid.

Leenhardt, M. (1997)[1947]: Do kamo. La persona y el mito en el mundo melanesio. Paidós, Barcelona.

Machin, A. (2009): The role of the individual agent in Acheulean biface variability. Journal of Social Archaeo$\log y, 9$ (1): 35-58.

Mezrich, B. (2010): Multimillonarios por accidente: El nacimiento de Facebook. Una historia de sexo, dinero, talento, y traición. Alienta, Madrid.

Midgley, M. (2004): The Myths We Live By. Routledge Classics, Londres.

Montón-Subías, S.; SÁnchez-Romero, M. (eds.) (2008). Engendering Social Dynamics. The Archaeology of Maintenance Activities. British Archaeological Reports (International Series), 1862. Archaeopress, Oxford.

Moore, H. (2000): Ethics and ontology: why agents and agency matter. Agency in Archaeology (M.-A. Dobres, J.Robb, eds.). Routledge, Londres: 259-63.

Morin, E. (2005)[1994]: Epistemología de la complejidad. Nuevos Paradigmas, Cultura y Subjetividad (D. F. Schnitman et al., eds.), Paidós, Buenos Aires: 421-53.

Morris, C. (1987): The Discovery of the Individual. 1050-1200. University of Toronto Press/Medieval Academy of America, Toronto.

Olsen, B. (2010): In Defense of Things. Archaeology and the Archaeology of Objects. AltaMira Press, Lanham, Maryland.

Olson, D.R. (1998)[1994]: El mundo sobre papel. El impacto de la escritura y la lectura en la estructura del conocimiento. Gedisa, Barcelona.

Ong, W. (1996)[1982]: Oralidad y escritura. Tecnologías de la palabra. Fondo de Cultura Económica, México.

Ortner, S.B. (1996): Making Gender. The Politics and Erotics of Culture. Beacon Press, Boston.

RathJe, W.L. (1992): Rubbish!: the Archaeology of Garbage. Harpercollins, Nueva York.

Renfrew, C. (1988)[1973]: El alba de la civilización. La Revolución del Radiocarbono (C14) y la Europa Prehistórica. Istmo, Madrid.

Renfrew, C.; Cherry, J.F. (eds.) (1984): Peer polity interaction and socio-political change. Cambridge University Press, Cambridge.

Rogers, S.C. (1975): Female Forms of Power and the Myth of Male Dominance. American Ethnologist, 2(4):72757.

Rowlands, M. J. (1980): Kinship, alliance and exchange in the European Bronze Age. Settlement and Society in the British Later Bronze Age (J. Barret, R. Bradley, eds.), British Archaeological Reports (British Series), 83, Archaeopress, Oxford: 15-55.

Ruiz, R. (1992): Entrevista a William Rathje, "Los varones apenas dejan rastro en sus basuras". El País, 3 noviembre 1992. 
Ruiz-GÁLVEz, M. L. (1992): La novia vendida: orfebrería, herencia y agricultura. SPAL, 1: 219-51.

Ruiz-Gálvez, M. L. (1998): Peripheral, but not that much...! Intercâmbio e Comércio: as "Economías" da Idade de Bronze (I) (V. Oliveira Jorge, ed.), Monografía de Trabalhos de Arqueología, 10: 101-113.

Ruiz-GálVez, M. L. (2009): ¿Qué hace un micénico como tú en un sitio como éste? Andalucía entre el colapso de los palacios y la presencia semita. Trabajos de Prehistoria, 66 (2): 93-118.

Sanday, P.R. (1981): Female Power and Male Dominance. Cambridge University Press, Cambridge.

SennetT, R. (2009) [1998]: La corrosión del carácter. Las consecuencias personales del trabajo en el nuevo capitalismo. Anagrama, Madrid.

Shanks, M.; Tilley, C.Y. (1992): Re-constructing Archaeology: Theory and Practice. Routledge, Londres.

SherRatT, A. (1981): Plough and pastoralism: aspects of the secondary products revolution. Pattern of the past. Studies in honour of David Clarke (I. Hodder, G. Isaac, N. Hammond, eds.). Cambridge University Press, Cambridge: 261-303.

SHERRATT, A. (1986): Wool, Wheels and Ploughmarks: Local Developments or Outside Introductions in Neolithic Europe? Institute of Archaeology Bulletin, 23: 1-15.

Sherratt, A. (1987): Cups That Cheered. Bell Beakers of the Western Mediterranean. Definition, Interpretation, Theory and New Site Data (W.H. Waldren, R.C. Kennard, eds.), The Oxford International Conference, 1986. British Archaeological Reports (International Series) 331(i): 81-113.

SkAR, S. (1981): Andean women and the concept of space/time. Women and Space. Ground Rules and Social Maps (S. Ardener, ed.), Croom Helm in association with the Oxford University women's studies committee, Londres: $35-49$.

Sørensen, M.L. S. (1997): Reading dress: the construction of social categories and identities in Bronze Age Europe. Journal of European Archaeology, 5.1: 93-114.

TARLOW, S. (2000): Emotion in Archaeology. Current Anthropology, 41(5): 713-46.

TAYLOR, A.C. (1996): The soul's body and its states: an amazonian perspective of the nature of being human. The Journal of the Royal Anthropological Institute, 2 (2): 201-15.

Thомаs, J. (2004): Archaeology and Modernity. Routledge, Londres.

Thornton, R.J. (1980): Space, Time and Culture among the Iraqw of Tanzania. Academic Press, Nueva York.

Torres López, J. (2010): La crisis de las hipotecas basura. ¿Por qué se cayó todo y no se ha hundido nada? Sequitur, Madrid.

TREHERNE, P. (1995): The warrior's beauty: the masculine body and self-identity in Bronze-Age Europe. Journal of European Archaeology, 3,1: 105-44.

TURNER, T. (1995): Social body and embodied subject: bodiliness, subjectivity and sociality among the Kayapó. Cultural Anthropology, 10(2): 143-70.

ViriLIO, P. (2005): The Paul Virilio Reader (S. Redhead, ed.). Columbia University Press, Nueva York.

Viveiros de CAstro, E. (1996): Os pronomes cosmológicos e o perspectivismo ameríndio. Maná, 2(2): 115-44.

Webmoor, T.; Witmore, C. (2008): Things Are Us! A Commentary on Human/Things Relations under the Banner of a 'Social' Archaeology. Norwegian Archaeological Review, 41(1): 53-70.

Weintraub, Karl J. (1993)[1978]: La formación de la individualidad. Autobiografía e Historia. Megazul-Endymion Madrid. 